\title{
Impermeabilização do espaço urbano de porto união, santa catarina: estudo de caso com fotografias aéreas digitais de altíssima resolução
}

\author{
Waterproofing of urban space porto união, santa catarina: a case study with digital \\ aerial photographs high resolution
}

\author{
Jerusa Tonete Felde ${ }^{* 1}$, Cristian Whitman Bueno da Silva Reinelli ${ }^{2}$ e \\ Paulo Costa de Oliveira Filho ${ }^{3}$
${ }^{1}$ Graduada em Engenharia Ambiental ,Bolsista da Fundação Araucaria do Curso de Engenharia Ambiental da Universidade Estadual do Centro-Oeste/UNICENTRO, PR, Brasil
${ }^{2}$ Mestre em ciências florestais, Programa de Pós-Graduação em Engenharia Florestal, área de atuação Geotecnologias e recursos hídricos, PR, Brasil \\ ${ }^{3}$ Doutor em ciências florestais, Universidade Estadual do Centro-Oeste do Paraná - UNICENTRO-PR/ Professor \\ Associado do Departamento de Engenharia Ambiental - Campus Irati, PR, Brasil
}

\begin{abstract}
Resumo
O presente trabalho teve como objetivo o mapeamento do grau de impermeabilização de grande parte do bairro Santa Rosa, município de Porto União, Santa Catarina. Inicialmente foi realizada a classificação detalhada de uso e ocupação do solo da área de estudo através da interpretação e vetorização de fotografias aéreas digitais de altíssima resolução. A seguir, foi adotada uma metodologia simplificada para avaliar o grau de impermeabilização das superficies mapeadas e posteriormente foi realizada a reclassificação e classe de impermeabilização. Os resultados indicaram que de todas as superfícies avaliadas e mapeadas obteve-se 34,95\% de superfícies impermeáveis.
\end{abstract}

Palavras-chave: Sensoriamento remoto. Taxa de ocupação do solo. Drenagem urbana.

\begin{abstract}
This study aimed to map the degree of sealing of much of the neighborhood Santa Rosa, Porto União City, Santa Catarina. Initially, the detailed use and land cover of the study area through interpretation and vectorization of digital aerial photographs of high resolution was carried. The following is a simplified methodology was adopted to evaluate the degree of sealing of surfaces and subsequently mapped to class reclassification and sealing was performed. The results indicated that all surfaces evaluated and mapped gave $34.95 \%$ impervious surfaces.
\end{abstract}

Keywords: Remote sensing. Occupancy soil. Urban drainage. 


\section{Introdução}

A interpretação fotográfica é uma técnica empregada desde o nascimento das fotografias que se deu em 1840. A fotointerpretação foi muito difundida, e é utilizada por diversos profissionais, em diferentes áreas de atuação como a geologia, agricultura, silvicultura, vida silvestre, aplicação militar, análise urbana e planejamento ambiental. A técnica de interpretação de fotografias aéreas quando aplicadas em projetos ambientais distintos apresenta algumas vantagens quando comparada com técnicas comuns de levantamentos de campo, dentre essas vantagens podemos citar maior rapidez, informações com níveis superiores e ainda um custo menor (DISPERATI, SANTOS E ZERDA, 2007). Os mesmos autores ainda afirmam que dependendo do nível de resultado desejado, é preciso somente uma análise simples das fotografias aéreas e em seguida a interpretação das mesmas, porém às vezes é necessário um trabalho no qual a interpretação deva seguir um modelo adequado para que no final se obtenha um mapa temático, a partir do qual pode-se conseguir áreas e porcentagens dos tipos mapeados. Os resultados destes trabalhos obtidos a partir da fotointerpretação sejam mapas ou outros, ou simplesmente as fotografias em si, podem ser utilizadas por profissionais para auxiliar na tomada de decisões, planejamentos ou execução de projetos que abranjam a área ambiental.

Atualmente com a maior tendência de interpretar fotografias aéreas em meio digital, os foto interpretes contam com uma grande variedade de câmeras como a que destacaremos no presente trabalho - ADS40 ( Airborne Digital Sensor), e ferramentas de processamento de imagens. Esta técnica exige hardware e software apropriados. As fotografias deste estudo foram analisadas no modo monoscópico, utilizando um software de processamento de imagens, o SIG (Sistema de Informações Geográficas) SPRING versão 5.2.4. Para facilitar a identificação das classes de uso e ocupação do solo definidas neste trabalho, foram utilizadas imagens panorâmicas em $360^{\circ}$ na perspectiva de visão da rua do Google Earth street view.

Ribeiro (2007) pôde avaliar a evolução da impermeabilização do solo da bacia hidrográfica do Rio Bacacheri na cidade de Curitiba fazendo uma análise multitemporal a partir da fotointerpretação de fotos aéreas dos anos 1952, 1962, 1980 e 2000, e processamento de dados em ambiente SIG. Neste estudo, os tipos foram classificados em permeáveis, semipermeáveis e impermeáveis.

Sebusiani e Bettine (2011) realizaram também uma análise cronológica utilizando fotos aéreas de 1994 em escala 1:5.000, e uma imagem de satélite de 2007, obtida através do sistema Google Earth, para um estudo de impermeabilização do solo na região da Bacia do Córrego da Fazenda Santa Cândida que é um afluente do Ribeirão das Anhumas, o qual nasce no centro de Campinas/SP. Os níveis de impermeabilização foram classificados em alto, médio e baixo.
O processo de urbanização ocorrido no Brasil foi intensificado nas décadas de 50 e 60 com o movimento rural-urbano. Tucci (2003) aborda que hoje a propensão à urbanização provoca expressivos impactos no meio ambiente, como aumento do nível e frequência das inundações, redução da qualidade da água e aumento de lixo que é transportado no escoamento pluvial.

Segundo Tucci (2000), existem três principais problemas causados pelo crescimento populacional, o primeiro deles é o aumento na procura por recursos hídricos que leva a um desenvolvimento diretamente proporcional à quantia de água disponível. Em segundo está o controle de enchentes, estas são causadas pela progressiva substituição da rede de drenagem natural por estruturas artificiais aumentando grandemente as áreas impermeáveis, com isso há um maior volume de água pluvial que é escoada mais velozmente.

Os mesmos autores afirmam que a quantidade de água penetrada no solo é reduzida, por conseguinte a vazão dos rios diminui nos períodos não chuvosos, visto que nesses períodos os rios são alimentados pelos aquíferos que ficam menos recarregados. Somado a isso está o fato de que dejetos e substâncias são levados aos mananciais pelas enxurradas contaminando as águas, causando o terceiro problema: a poluição.

Justino et al. (2011) citam que as consequências diretas das enchentes e inundações nas áreas urbanas são perdas materiais, perdas de vidas humanas, e inúmeros impactos ambientais.

Tucci (2003) afirma que a utilização de canalização para drenagem, muito utilizada no Brasil, pode agravar o problema ao invés de resolvê-lo, pois além dos custos de obras estruturais como esta serem altos, ainda transfere a inundação para jusante da bacia hidrográfica.

Araújo et al. (2000) comentam que há uma tendência na área de drenagem urbana de utilização de um dispositivo que aumente a infiltração e retarde o escoamento, um exemplo disso é o pavimento permeável, que é capaz de reduzir volumes de escoamento superficial e vazões de pico em níveis semelhantes aos que eram observados antes da intensa urbanização.

Sobre o desempenho de pavimentos permeáveis como medida mitigadora da impermeabilização do solo urbano Pinto (2011) afirma que por causa do impacto gerado pela impermeabilização, há uma demanda por dispositivos que contribuam para amenizar os impactos que esta traz ao ambiente e tentar reverter esse fenômeno, e o pavimento permeável é muito eficiente nesse sentido, pois promove a infiltração da água da chuva no solo urbano e atua como um retardador do tempo de pico das cheias, além de permitir a recarga do lençol freático. A autora ainda afirma que os pavimentos permeáveis mais comumente encontrados são os blocos de concreto (vazados ou não), e o revestimento poroso que também é conhecido como concreto asfáltico poroso, ou camada porosa de atrito (CPA), esses pavimentos podem ser usados em calçadas, estacionamentos, ruas 
de tráfego leve, etc.

Os pavimentos permeáveis só são viáveis quando instalados em locais que tenham rampas suaves, solo com boa capacidade de infiltração e lençol freático relativamente profundo. (SCHUELLER,1987 Apud ARAÚJO, TUCCI E GOLDENFUM,2000.)

Cruz et al. (1999) propõem a aplicação de estruturas simples que juntas com o sistema de drenagem convencional proporcionam a diminuição de vazões e volumes de água escoados, reduzindo deste modo um dos maiores problemas no ambiente urbano que são as cheias. Dentre as estruturas propostas estão os microreservatórios de detenção e as trincheiras de infiltração.

No mesmo estudo os autores ainda comentam que o microrreservatório de detenção é mais viável se aplicado à microdrenagem, pois a implementação é mais simples e rápida, e demanda um espaço menor do que aquele que a macrodrenagem necessita. Estes dispositivos podem ser aplicados em jardins, praças e quintais, e ainda podem servir para abastecimento de água que pode ser usada posteriormente para lavar superfícies e automóveis e irrigação. As trincheiras de infiltração são dispositivos usados para armazenar a água da chuva até que ela tenha infiltrado no solo. $\mathrm{O}$ autor cita algumas vantagens deste dispositivo, entre elas estão a diminuição da rede de microdrenagem local, pois o volume de água que iria passar pela rede agora é infiltrada no solo, outras vantagens são a redução do risco de inundações, diminuição da poluição visto que o lixo não é transportado em grandes quantidades pelas águas superficiais, recarga das águas subterrâneas, fácil implementação (parques, praças, calçadas, ruas) e baixo custo. $\mathrm{O}$ autor conclui que a utilização destes dispositivos é eficiente para amenizar os impactos causados pela impermeabilização do espaço urbano e no controle do escoamento superficial.

Este trabalho tem como objetivo a interpretação de fotografias aéreas digitais para o mapeamento e obtenção da distribuição espacial das áreas verdes e construídas, assim como as taxas de ocupação/impermeabilização do solo urbano de uma área urbana da cidade de Porto União, Santa Catarina.

\section{Metodologia}

\subsection{Localização da Área de Estudo}

A área de estudo está localizada em uma parcela da área urbana do município de Porto União, o qual esta localizado no Planalto Norte do estado de Santa Catarina (Figura 1). A cidade é banhada pelos Rios Iguaçu e seus afluentes Jangada, Timbó, Pintado, dos Pardos, Bonito e

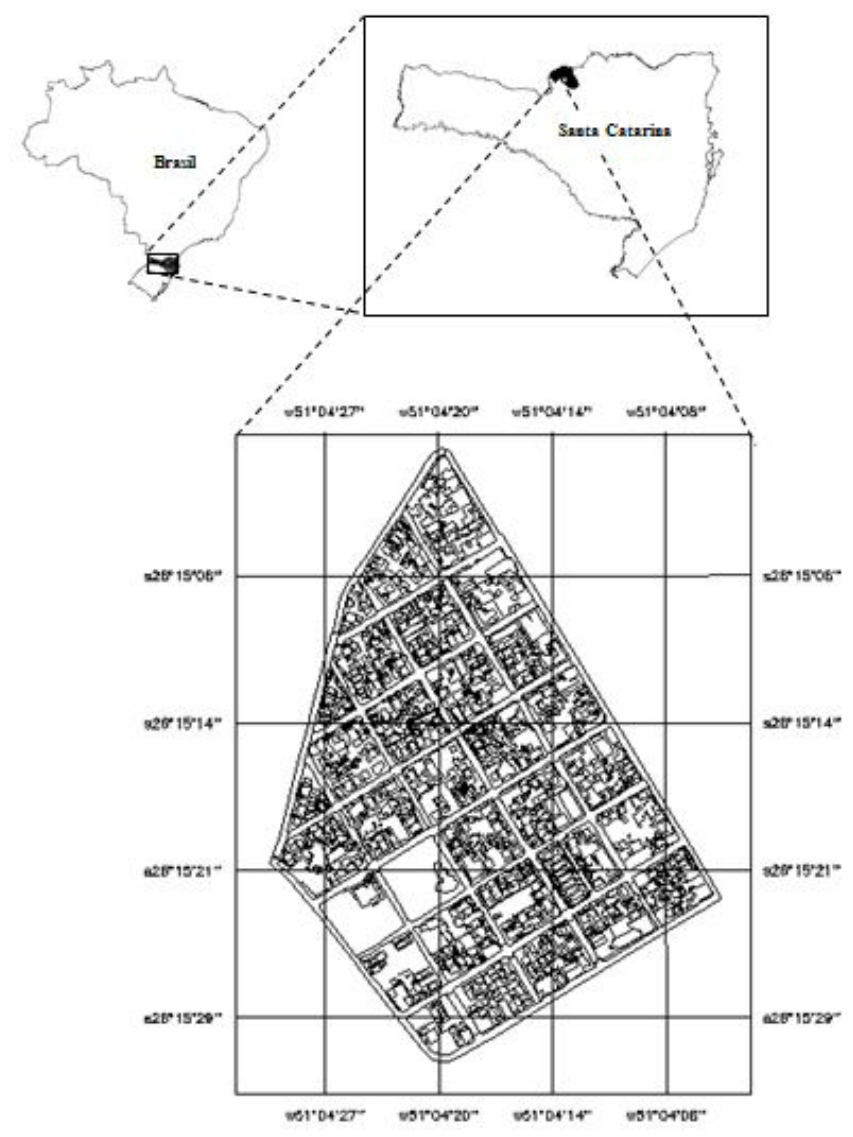

Figura 1. Localização da área de estudo, no sul do Brasil, norte do estado de Santa Catarina, no município de Porto União, parte do bairro Santa Rosa. 
Tamanduá. Com população de 34.551 habitantes, sendo 28.266 pessoas residentes da área urbana. O território da cidade tem $845,340 \mathrm{~km}^{2}$ e a densidade demográfica é de 39,62 hab/ $/ \mathrm{km}^{2}$, segundo senso do IBGE 2010.

\subsection{Coleta e Processamento dos dados}

Foram utilizadas ortoimagens recentes do ano de 2012 de alta resolução espacial, as quais foram obtidas através do sensor ADS40 Sensor Digital Airborne, o qual une precisão fotogramétrica com posição acurada dos dados processados com capacidades multiespectrais de análise e interpretação de imagens. Foi utilizado o aplicativo de domínio público SPRING - Sistema de Processamento de Informações Georreferenciadas, versão 5.2.4., e para facilitar a identificação das classes de uso e ocupação do solo definidas neste trabalho, foram utilizadas imagens panorâmicas em $360^{\circ}$ no nível da rua do Google Earth Street View, que utiliza técnicas de fotogrametria de superfície para simular a sensação de estar dentro das ruas de uma cidade. O mapeamento foi realizado utilizando a interpretação cognitiva e a técnica de vetorização sobre tela através da fotointerpretação em ambiente computacional, seguido de uma associação dos polígonos às classes pré-definidas. Também foram obtidas fotos in loco da área de estudo, e das diferentes classes pré-estabelecidas.

Ao final utilizando o software SCARTA 5.2.6 foi elaborado um mapa temático contendo a distribuição das 13 classes identificadas no ambiente estudado, suas respectivas áreas e ocupação percentual em relação à área total.

Com a delimitação dos usos e ocupação do solo urbano, foram realizados ensaios de impermeabilização destas áreas. Esta etapa foi realizada a partir da determinação dos grupos de classes identificadas, seguindo uma padronização de valores que foram adotados, estabelecidos em $\mathrm{cm}^{3} / \mathrm{cm}^{2}$. Para determinar os valores de permeabilidade foram utilizados 2 cilindros graduados, um com área basal menor para superfícies homogêneas e outro com área basal maior buscando abranger uma maior área de permeabilidade. Os cilindros foram devidamente alocados sobre as diferentes superfícies, e isolados para impedir o vazamento de água. A seguir, foi adicionado água continuamente pelo período de 5 minutos para a manutenção do nível dentro de cada recipiente, sendo quantificado o volume de água infiltrada. Após estes processos, foram anotados os valores, e calculadas as quantidades de água que permearam em $\mathrm{cm}^{3}$ por $\mathrm{cm}^{2}$ de área basal. Tomou-se o cuidado para que as áreas estivessem em condições naturais de chuvas, sem apresentar saturação por umidade. Os instrumentos dos ensaios estão representados na figura 2. Foram realizados 3 ensaios para cada classe, sendo utilizados os valores médios.

A seguir foi realizada a reclassificação das classes de uso e ocupação do solo urbano para classes de impermeabilização. Determinou-se, além do novo mapa temático, os valores de área em metros quadrados e respectivas taxas de ocupação (\%).

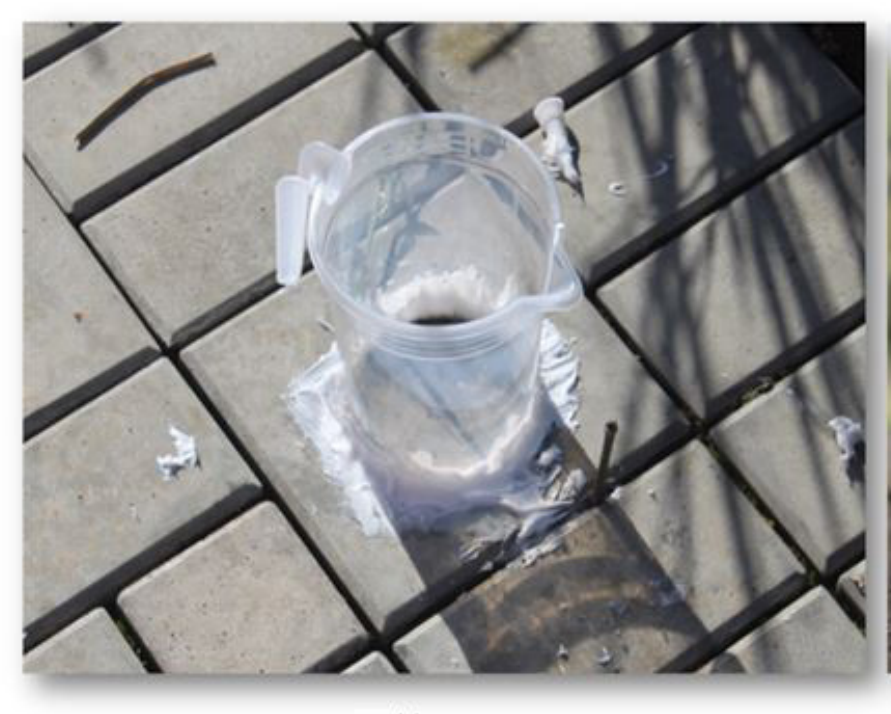

A)

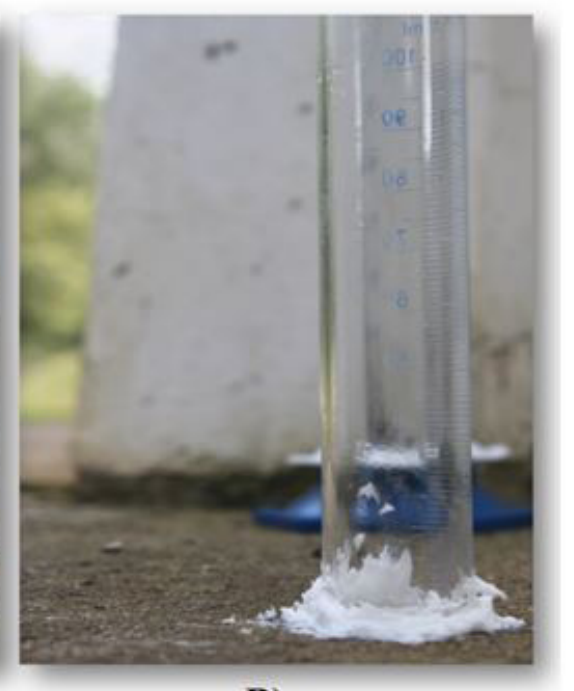

B)

Figura 2. Instrumentos utilizados nos ensaios de impermeabilização, para área basal maior buscando compreender uma maior área para a permeabilidade (Figura 1-A) e outro para área basal menor para superfícies homogêneas (Figura 1-B).

Fonte: Elaborada pelos autores. 


\section{Resultados e discussão}

\subsection{Classes de uso e ocupação do solo urbano}

Após os trabalhos de interpretação e classificação do uso e ocupação do solo urbano, foram obtidos os valores por área em $\mathrm{m}^{2}$ e em percentual para as classes pré-definidas apresentadas na tabela 1 e distribuídas espacialmente no mapa temático da figura 3.

A interpretação das fotografias digitais de alta resolução permitiu um nível de detalhamento bastante alto dos diversos materiais componentes da estrutura urbana, proporcionando um resultado espacial bastante confiável. A distribuição espacial das classes além das

Tabela 1. Área total e percentagens das classes mapeadas.

\begin{tabular}{clcc} 
& \multicolumn{1}{c}{$\begin{array}{c}\text { Classe de Uso e } \\
\text { Ocupação }\end{array}$} & Área $\left(\mathbf{m}^{2}\right)$ & $\begin{array}{c}\text { Taxa de } \\
\text { Ocupação (\%) }\end{array}$ \\
\hline $\mathbf{1}$ & Solo Exposto & $33.713,0$ & 9,56 \\
\hline $\mathbf{2}$ & Vegetação Rasteira & $121.427,0$ & 34,44 \\
\hline $\mathbf{3}$ & Vegetação Arbórea & $15.361,0$ & 4,36 \\
\hline $\mathbf{4}$ & Brita & $13.778,0$ & 3,91 \\
\hline $\mathbf{5}$ & Bloquete sextavado & $6.360,0$ & 1,80 \\
\hline $\mathbf{6}$ & Asfalto & $31.521,0$ & 8,83 \\
\hline $\mathbf{7}$ & Pedras paralelepípedo & $8.580,0$ & 2,43 \\
\hline $\mathbf{8}$ & Concreto & $16.586,0$ & 4,70 \\
\hline $\mathbf{9}$ & Blocos intertravados retangulares & 107,0 & 0,03 \\
\hline $\mathbf{1 0}$ & Cascalho & 495,0 & 0,14 \\
\hline $\mathbf{1 1}$ & Pó de pedra & 73,0 & 0,02 \\
\hline $\mathbf{1 2}$ & Telhados e coberturas & $74.953,0$ & 21,26 \\
\hline $\mathbf{1 3}$ & Estradas compactadas & $29.653,0$ & 8,41 \\
\hline & Total & $352.607,0$ & $\mathbf{1 0 0}$ \\
\hline
\end{tabular}

Fonte: Elaborada pelos autores.

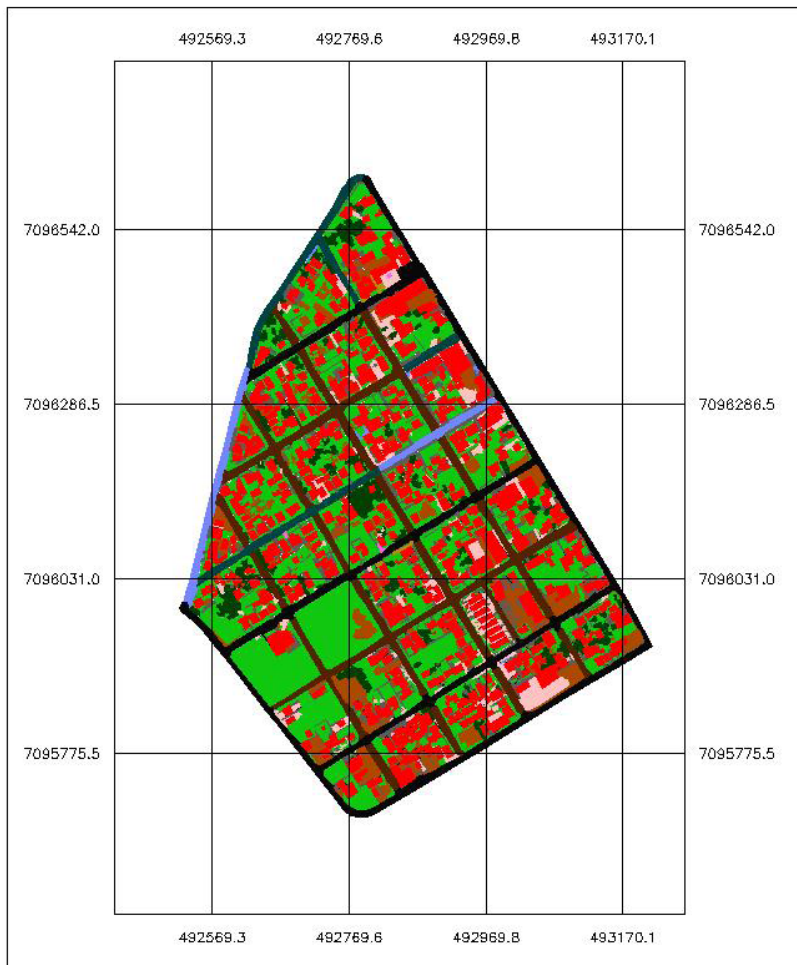

Classificacão do uso do solo em parte da área urbana de Porto União - SC

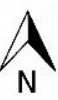

Sistema de Projeção UTM - Fuso 22 DATUM WGS84
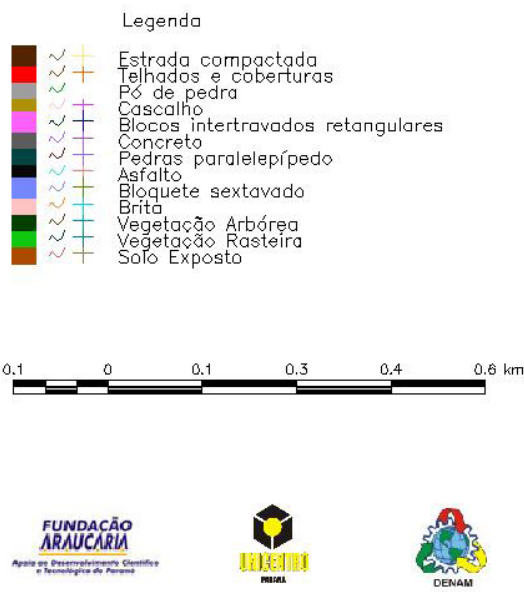

Figura 3. Mapa da classificação do uso do solo na área do estudo.

Fonte: Elaborada pelos autores. 
taxas de ocupação do solo urbano, permitem estudos de permeabilidade do solo, de grande utilidade à gestão da urbanização como também ao planejamento de escoamento e drenagem até o gerenciamento de áreas sujeitas à inundação.
O quadro 1 apresenta as classes de uso e ocupação da área de estudo, do espaço urbano de Porto União, Santa Catarina, sua descrição, um segmento de imagem obtido através do Google Earth Street View 2011 utilizado para checagem e uma fotografia "in loco" 2014 de cada superfície ou classe identificada em campo.

Quadro 1. Classes do uso e ocupação do espaço urbano de Porto União - SC.

\begin{tabular}{|c|c|c|c|}
\hline Classe & Descrição & $\begin{array}{c}\text { Imagens GoogleEarth } \\
\text { Street View }\end{array}$ & $\begin{array}{c}\text { Fotografias "in loco" } \\
2014\end{array}$ \\
\hline Solo Exposto & $\begin{array}{l}\text { Solo sem } \\
\text { qualquer } \\
\text { vegetação }\end{array}$ & & \\
\hline $\begin{array}{l}\text { Vegetação } \\
\text { Rasteira }\end{array}$ & $\begin{array}{l}\text { Vegetação pouco } \\
\text { desenvolvida. } \\
\text { Grama e capim. }\end{array}$ & & \\
\hline $\begin{array}{l}\text { Vegetação } \\
\text { Arbórea }\end{array}$ & $\begin{array}{l}\text { Vegetação } \\
\text { constituída por } \\
\text { árvores de } \\
\text { maior porte. }\end{array}$ & & 13 \\
\hline Brita & $\begin{array}{l}\text { Rocha quebrada } \\
\text { mecanicamente } \\
\text { em diferentes } \\
\text { tamanhos de } \\
\text { fragmentos. }\end{array}$ & & \\
\hline $\begin{array}{l}\text { Bloquete } \\
\text { sextavado }\end{array}$ & $\begin{array}{l}\text { É o piso } \\
\text { intertravado de } \\
\text { concreto } \\
\text { hexagonal. }\end{array}$ & & \\
\hline Asfalto & $\begin{array}{l}\text { Betume espesso, } \\
\text { de material } \\
\text { aglutinante } \\
\text { escuro e } \\
\text { reluzente, de } \\
\text { estrutura sólida. }\end{array}$ & & \\
\hline
\end{tabular}


Quadro 1. Continuação...

\begin{tabular}{|c|c|c|c|}
\hline Classe & Descrição & $\begin{array}{c}\text { Imagens GoogleEarth } \\
\text { Street View }\end{array}$ & $\begin{array}{c}\text { Fotografias "in loco" } \\
2014\end{array}$ \\
\hline $\begin{array}{l}\text { Pedras } \\
\text { paralelepipe. }\end{array}$ & $\begin{array}{l}\text { Blocos } \\
\text { paralelepípedos } \\
\text { provenientes de } \\
\text { rochas } \\
\text { (pedreiras) }\end{array}$ & & \\
\hline Concreto & $\begin{array}{l}\text { Mistura de } \\
\text { cimento, pedra, } \\
\text { areia e água. }\end{array}$ & & \\
\hline Blocos & Blocos de & & \\
\hline Cascalho & $\begin{array}{l}\text { Proveniente de } \\
\text { rochas cristalinas } \\
\text { cuja degradação } \\
\text { se dá por } \\
\text { processos } \\
\text { naturais. }\end{array}$ & & \\
\hline Pó de pedra & $\begin{array}{l}\text { Material } \\
\text { proveniente de } \\
\text { calcário calcítico. }\end{array}$ & & \\
\hline $\begin{array}{l}\text { Estrada } \\
\text { compactada }\end{array}$ & $\begin{array}{l}\text { Área de transito } \\
\text { de automóveis, } \\
\text { solo compactado. }\end{array}$ & & \\
\hline
\end{tabular}

Fonte: Elaborada pelos autores. 


\subsection{Permeabilidades das Classes de Uso e Ocu- pação do Solo}

A partir das classes de uso e ocupação pré-definidas conforme a tabela 2, foi então realizado o estudo da capacidade de permeabilidade em cada uma das superfícies.

Apesar de um rigoroso cuidado para o detalhamento das permeabilidades de diversos materiais de ocupação do solo encontrados nesta área urbana, alguns índices não apresentaram diferenças de comportamentos em sua capacidade de permeabilidade, e outros com capacidades de permeabilidade influenciadas pela camada sub-superficial a qual eles recobrem. A partir das capacidades de permeabilidade apresentadas nos testes, as classes de uso e ocupação, ou as diferentes superfícies intraurbanas, foram classificadas em grupos por similaridade.

Os valores apresentados para a classificação foram discriminados a partir dos testes de campo, utilizando-se a mesma metodologia, e desconsiderando outros coeficientes de influência, tais como escoamento superficial e tempos mais prolongados de exposição ambiental e sujeitos à influência da chuva e vento, assim como a declividade.

Dentre as classes representadas na tabela 2 algumas possuem características semelhantes na capacidade de permeabilidade de água, sendo classificadas nos grupos como impermeável, baixa permeabilidade, alta permeabilidade, solo natural e dependente do meio. Cada uma com suas capacidades, conforme listadas na tabela 2, e especificadas suas respectivas áreas e taxas de ocupação na tabela 3 e distribuição espacial através do mapa temático da figura 4 .

Os resultados da tabela 3 indicaram que de todas as superfícies avaliadas e mapeadas obteve-se $34,90 \%$ de superfícies impermeáveis. Somando-se esta classe com as áreas de baixa permeabilidade chegou-se a $45,76 \%$. A figura 4 evidencia em algumas quadras uma alta concentração de áreas impermeáveis. Desta forma, a distribuição espacial dos resultados deve ser considerada pois as quadras que se apresentam classificadas como solo natural, indicam áreas privadas que logo poderão ser urbanizadas.

\subsubsection{Coberturas Impermeáveis}

São as áreas compreendidas com uso ou cobertura de ocupação representadas no mapa da Figura 2 como asfalto, coberturas e telhados, e concreto. Essas áreas não apresentaram nenhuma capacidade de permeabilidade da água em seus testes, gerando assim o índice de permeabilidade igual a 0 (zero).

\subsubsection{Coberturas de Baixa Permeabilidade}

Esta classe é composta pelas ocupações com pedras do tipo "paralelepípedos irregulares" e áreas cobertas com pó de pedra e estradas de solo compactado, estas são áreas que apresentaram um índice de permeabilidade

Tabela 2. Classes de uso e ocupação do solo agrupadas por nível de impermeabilização

\begin{tabular}{cccc} 
Classe & Valor Lógico & $\begin{array}{c}\text { Valor } \\
\text { Analisado } \\
\left(\mathbf{c m}^{3} / \mathbf{c m}^{2}\right)\end{array}$ & $\begin{array}{c}\text { Nível de } \\
\text { impermeabilização }\end{array}$ \\
\hline Asfato & 0 & 0 & Impermeável \\
\hline Telhados e Coberturas & 0 & 0 & Impermeável \\
\hline Concreto & 0 & 0 & Impermeável \\
\hline Pedras paralelepípedo & 1 & 1 & Baixa permeabilidade \\
\hline Pó de pedra & 1 & 1 & Baixa permeabilidade \\
\hline Estradas compactadas & 1 & 1 & Baixa permeabilidade \\
\hline Blocos intertravados retangulares & 2 & 10,5 & Alta permeabilidade \\
\hline Bloquete sextavado & 2 & 10,5 & Alta permeabilidade \\
\hline Solo exposto & 3 & 4,3 & Solo natural \\
\hline Vegetação arbórea & 3 & 4,3 & Solo natural \\
\hline Vegetação rasteira & 3 & 4,3 & Solo natural \\
\hline Brita & Dependente & & Dependente \\
\hline Cascalho & Dependente & & Dependente \\
\hline
\end{tabular}

Fonte: Elaborada pelos autores. 
Tabela 3. Área total e taxas de ocupação das classes de impermeabilização.

\begin{tabular}{lrc}
$\begin{array}{c}\text { Classe de } \\
\text { Impermeabilização }\end{array}$ & $\begin{array}{c}\text { Área } \\
\left(\mathbf{m}^{2}\right)\end{array}$ & $\begin{array}{c}\text { Taxa de } \\
\text { Ocupação (\%) }\end{array}$ \\
\hline Impermeável & $123.060,0$ & 34,90 \\
\hline Baixa Permeabilidade & $38.306,0$ & 10,86 \\
\hline Alta Permeabilidade & $6.467,0$ & 1,83 \\
\hline Solo Natural & $170.501,0$ & 48,35 \\
\hline Dependente & $14.273,0$ & 4,05 \\
\hline Total & $\mathbf{3 5 2 . 6 0 7 , 0}$ & $\mathbf{1 0 0}$ \\
\hline
\end{tabular}

Fonte: Elaborada pelos autores.

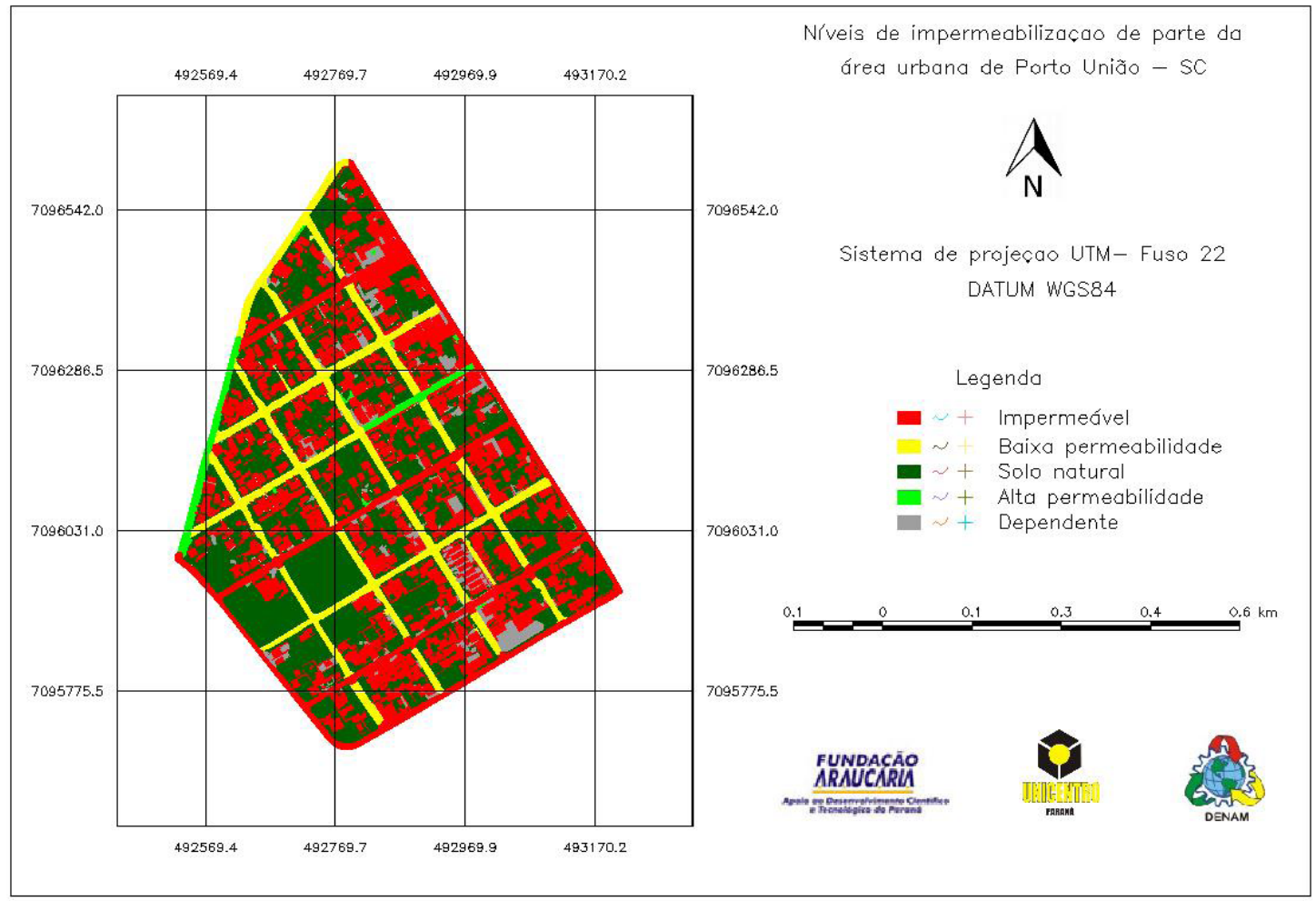

Figura 4. Mapa dos níveis de impermeabilização em parte da área urbana de Porto União - SC.

Fonte: Elaborada pelos autores.

muito baixo, tanto as calçadas e estradas com pedras irregulares, por serem compostas de rejunte de cimento ou então desenvolveu uma ocupação com briófitas em rejuntes de terra, impedindo a permeabilidade da água, o mesmo ocorrendo nas classes de estradas compactadas, ou cobertas com pó de Pedra, dos quais a compactação, para manutenção e estrutura das estradas, o tornam impermeáveis.

\subsubsection{Coberturas de Alta Permeabilidade}

Estas classes se identificaram com particularidades nas coberturas de blocos intertravados retangulares e bloquetes sextavados, apesar da superfície destes materiais serem de concreto impermeável, as ranhuras apresentadas entre cada bloco permitem a passagem da água, e como particularidades da construção destas superfícies, está o fato que devem ser niveladas no solo e, para isto, é necessário que a base seja composta normalmente de areia, permitindo um rápido escoamento da agua por baixo da estrutura de concreto, sendo assim, com testes de área limitada, e com tempo limitado na exposição de agua, não se possui condições de apresentação real da capacidade de permeabilidade e escoamento subsuperficial destas áreas, sendo assim, com uma exposição curta a chuvas, estas coberturas permitem uma rápida permeabilidade entre os blocos, e condições de escoamento abaixo da superfície, sempre considerando a espessura desta área de fixação dos blocos. 


\subsubsection{Cobertura de Solo Natural}

Ocorrem em áreas verdes com árvores, gramados ou o solo exposto. Os valores destas classes foram muito similares considerando somente o nível de impermeabilização. Entretanto, há diferenças, se for considerado que o solo exposto sofre maior impacto das gotas de chuva, que podem ser amenizadas por uma cobertura vegetal rasteira e com maior eficiência em coberturas arbóreas, também reduzindo a velocidade do escoamento superficial.

\subsubsection{Cobertura do solo dependente}

Esta classe, atribuída aos grupos "Brita" e "Cascalho", são muito dependentes da camada subsuperficial a qual eles recobrem, pois a sua permeabilidade é muito alta, sendo limitada pela camada abaixo, podendo ser solo exposto, solo compactado (estradas), pó de pedra, entre outros inúmeros casos encontrados, o que impossibilita a determinação pela identificação da permeabilidade somente pela imagem aérea, mas haveria a necessidade de identificação e análise de cada superfície individualizada em campo.

\section{Conclusões}

- A utilização das imagens fotográficas digitais de 40 centímetros de resolução espacial permitiu um grande detalhamento das superfícies intraurbanas;

- A utilização da ferramenta Google Street View permitiu a verificação e elucidação de inúmeros casos onde os alvos apresentavam respostas espectrais semelhantes;

- A maior parte dos lotes ou terrenos apresentou uma área de boa permeabilidade do solo, porém a distribuição espacial apresenta locais de concentração de áreas impermeabilizadas.

- Os resultados indicaram que de todas as superfícies avaliadas e mapeadas obteve-se $34,95 \%$ de superfícies impermeáveis;

- Em geral a área de estudo apresenta uma boa distribuição espacial das áreas de solo natural o que de certa forma compensam a grande quantidade de áreas permeáveis em todas as quadras;

- A classe intitulada como "cobertura do solo dependente" mostrou-se importante devido à variação das camadas de assentamento imediatamente inferiores, às quais modificam bastante a capacidade de permeabilidade.

\section{Recomendações}

Recomenda-se estudos para a determinação de coeficientes de permeabilidade seguindo uma mesma metodologia para abranger toda a variabilidade de materiais de uso e cobertura em solo urbano.

\section{Agradecimentos}

Os autores agradecem à Fundação Araucária pela bolsa de pesquisa.

\section{Referências}

ARAÚJO ,P.R.; TUCCI, C.E.M.; GOLDENFUM JA Análise da eficiência dos pavimentos permeáveis na redução de escoamento superficial In: Tucci, CEM.; Motta, DML. Avaliação e controle da drenagem urbana. Porto Alegre, Brasil: Ed. Universidade/UFRGS, 2000.

CRUZ, M.A.S., ARAÚJO, P.R.; SOUZA, V.C.B. Estruturas de controle do escoamento urbano na microdrenagem. Trabalho apresentado no $13^{\circ}$ Simpósio Brasileiro de Recursos Hídricos, Belo Horizonte, Minas Gerais, Brasil, 1999.

DISPERATI, A.A.; SANTOS, J. R..;ZERDA, H.R. Fundamentos da Fotointerpretação In: DISPERATI, A. A.;AMARAL, R.F.do.; SCHULER, C.A.B. ( Organizadores) Fotografias Aéreas de Pequeno Formato- Aplicações Ambientais. Guarapuava : Ed. Unicentro, 2007. P.65-94.

IBGE-Instituto Brasileiro de Geografia e Estatística. Censo Demográfico 2010. Disponível em < http://www. cidades.ibge.gov.br/xtras/temas.php?lang=\&codmun= 421360\&idtema $=76 \&$ search $=$ santa-catarina $\% 7$ Cportouniao\%7Ccenso-demografico-2010:-cnefe-cadastronacional-de-enderecos-para-fins-estatisticos $>$. Acesso em : 16/01/2014 às $21 \mathrm{~h} 47 \mathrm{~min}$.

JUSTINO, E. A.; MARTINS P.H.P., Ed Carlo Rosa. Análise do efeito da impermeabilização dos solos urbanos na drenagem de água pluvial do município de UberlândiaMG. ESPAÇO EM REVISTA- UFG-CAC - vol. 13 nº 2 jul/dez. 2011 páginas: $16-38$

PINTO, L. L. C. A. O Desempenho de Pavimentos Permeáveis como Medida Mitigadora da Impermeabilização do Solo Urbano. 2011. 256p. Tese(Doutorado) - Escola Politécnica, Universidade de São Paulo, São Paulo, 2011.

PORTO UNIÃO, Lei Complementar № 025, de 13 de abril de 2007. Aprova o Plano Diretor de Desenvolvimento do município de Porto União, revoga a Lei $n^{\circ} 928$, de 30 de março de 1976, e suas alterações, e dá outras providências. 
PMPU - Prefeitura Municipal de Porto União-SC Aspectos Geográficos. Disponível em: http://www. portouniao.sc.gov.br/conteudo/?item $=11284 \& \mathrm{fa}=7737$ .Acesso em: 16/01/2014

RIBEIRO, N. C. Avaliação da impermeabilização e ocorrência de inundações na Bacia do Rio Bacacheri. Curitiba: UFPR, 2007. 123 f. Dissertação (Mestrado em Geologia Ambiental)- Curso de Pós-graduação em Geologia, Universidade Federal do Paraná, Curitiba, 2007.

SEBUSIANI, H. R. V.; BETTINE, S. do C. Metodologia de análise do uso e ocupação do solo em micro bacia urbana. Revista Brasileira de Gestão e Desenvolvimento Regional, Taubaté-SP, v. 7, n. 1, p. 256-285, jan-abr/2011.

TUCCI, C.E.M. Águas urbanas. In: TUCCI, C.E.M.; BERTONI, J.C. Inundações Urbanas na América do Sul. Porto Alegre: Associação Brasileira de Recursos Hídricos, 2003.

TUCCI, C.E.M.; VILLANUEVA, A.; CRUZ, M.A.S. Banco de eventos de cheias de bacias urbanas brasileiras. In: TUCCI, Carlos E.M.; MARQUES, D.M.L. da Motta. Avaliação e controle da drenagem urbana. - Porto Alegre: Ed. Universidade/UFRGS, 2000. 